\title{
CAMUS Y KAFKA: CUANDO NO HAY CASTILLO
}

\author{
Camus and Kafka: when there isn't a castle
}

\section{Alí Viquez Jiménez*}

\begin{abstract}
RESUMEN
En vista del interés manifiesto de Albert Camus hacia la obra kafkiana, este ensayo se propone comparar las novelas El castillo (Kafka) y El extranjero (Camus). Intenta leer a la una desde la otra, de manera tal que se contrasten algunas posibilidades y algunas limitaciones estéticas y filosóficas que surgen al compararlas. Concluye con la construcción de un marco de lectura que esclarece una relación precisa posible entre ambos textos.

Palabras clave: literatura comparada, literatura francesa, literatura checa, novela francesa contemporánea, novela checa contemporánea.
\end{abstract}

\begin{abstract}
In view of the interest expressed by Albert Camus to the Kafkaesque work, this essay is to compare the novel The Castle (Kafka) and The Stranger (Camus). It attempts to read the one from the other, so that some arising possibilities and some aesthetic and philosophical limitations, when compared, are contrasted. It concludes with the construction of an open reading frame that clarifies the possible precise relationship between the two texts.

Key Words: comparative literature, French literature, Czech literature, contemporary French novel, contemporary Czech novel.
\end{abstract}

Universidad de Costa Rica, Profesor, Escuela de Filología, Lingüística y Literatura. Costa Rica Correo electrónico: aliviquezj@gmail.com

Recepción: 10/2/16. Aceptación: 2/5/16. 


\section{Introducción}

En El mito de Sísifo, Camus subraya la importancia que para este texto tiene la obra de Kafka. El hecho es más significativo si tomamos en cuenta que el apartado que da título al volumen aparece ahora como el penúltimo del libro, pues Camus decidió hacer una edición aumentada al incluir "L'espoir et la'absurde dans l'œuvre de Franz Kafka" como apéndice final. La puerta para hacer una comparación entre la obra camusiana y la obra kafkiana está abierta entonces de manera explícita por parte del autor francés.

Una comparación entre $\mathrm{El}$ proceso y $\mathrm{El}$ extranjero parece más lógica, en razón de que en una y otra novela asistimos a un juicio de carácter simbólico. ${ }^{1}$ (El propio Camus comenta este rasgo a propósito de toda la obra kafkiana, también en El mito de Sísifo.) Mi intención en este ensayo es intentar una comparación menos evidente: la de El castillo y El extranjero. Tomo en cuenta lo siguiente: aunque se conocen declaraciones de Camus en las que se separa de Kafka, lo cierto es que estas se dan posteriormente a la escritura de El mito de Sísifo y El extranjero, que aparecieron casi simultáneamente, en $1942 .^{2}$ Además, como sabemos, lo que un autor exprese en su correspondencia no tiene por qué reflejarse en lo que expresan sus textos. Finalmente, en el apartado ya citado de El mito de Sísifo, Camus manifiesta su convicción de que El castillo es la obra culminante de Kafka; incluso, lo plantea en términos de que El proceso es una suerte de diagnóstico de la condición humana, en tanto en El castillo se "prescribe" ya un tratamiento para esa condición, ciertamente necesitada de ello. Las dos novelas se abordan por parte de Camus como complementarias, pero es la segunda la que va más allá, pues arranca donde ha quedado la primera. No me resulta abusivo pensar entonces que El castillo tiene relaciones importantes con El extranjero. En buena medida, ahondaré en las aseveraciones del propio Camus en $E l$ mito de Sisifo, tratando de determinar qué eco tuvieron en la novela de que Camus se ocupó más o menos paralelamente.

\section{Camus y el Sísifo literario}

Camus sabe bien que el símbolo kafkiano no admite una interpretación única y correcta. Hacia esto apunta desde el primer momento, cuando identifica el arte de Kafka con el arte de provocar la relectura: "Ses dénouements, ou ses absences de dénouement, suggèrent des explications, mais qui ne sont pas révélées en clair et qui exigent, pour apparaître fondées, que l'histoire soit relue sous un nouvel angle.» (Camus, 1951, p. 171).

La relectura se produce, pues, como consecuencia de una explicación que Kafka ha eludido darles a sus textos, los cuales carecen de desenlace. Pero la explicación que el lector se da cuando relee no es una explicación final, pues rigurosamente conduce a otra relectura. Camus no ha escrito que Kafka provoca solamente una segunda lectura; sus palabras bien pueden interpretarse como que la relectura de Kafka se enrumba a ser infinita: tras la segunda lectura, viene la tercera, luego la cuarta, la quinta... Sin decirlo de manera explícita, Camus sugiere que Kafka ha producido el texto que ejecuta el mito de Sísifo en términos literarios. Cuando el lector casi ha terminado su tarea, cuando se prepara para la explicación final, la ausencia de desenlace lo devuelve a la primera página.

Bueno es recordar aquí que Camus ha sostenido la posibilidad de un Sísifo dichoso. El trabajo inútil de cargar una piedra hasta lo alto de una colina, desde donde volverá a caer y Sísifo la volverá a cargar, y así por siempre... No lo ve Camus como un castigo necesariamente: puede Sísifo entender que su destino le pertenece, puede decirle "sí" a su eterno esfuerzo y enamorarse de él. La condición humana que se expresa en la figura de Sísifo es el absurdo causado por la incoherencia entre el deseo de realizar una tarea que lleve a resultados perdurables y la comprobación de que tales resultados se los lleva el viento. (No es quizá la mejor estrategia docente, pero al hablar de este tema a menudo detengo la clase y les pregunto a mis estudiantes: "Y ustedes, ¿para qué hacen tanto esfuerzo en 
leer libros y ganar cursos, cuando todo esfuerzo humano no tiene más destino que la muerte y el olvido?") Camus -ese incorregible optimista, dígase lo que se diga - pretende que es posible amar alegremente esa piedra que jamás podrá sostenerse en la meta: "Son rocher est sa chose." (1951, p. 112)

Así, según mi punto de vista (no se lo dice abiertamente), Camus procede a leer a Kafka inmediatamente después de afirmar esto como una forma de sugerir que en este autor se encuentra el mejor exponente de Sísifo en el plano literario. Kafka provoca la relectura: el lector debe volver al punto de inicio. Una y otra vez... El esfuerzo no produce un resultado final perdurable, la explicación definitiva del símbolo kafkiano, pero sí es posible llegar a enamorarse del destino que consiste en releer a Kafka una y otra vez. Esto puede ser válido para la experiencia entera de lectura literaria; Kafka viene a ser ese maestro que lo ilustra de manera privilegiada, pero al fin que estamos hablando de la literatura toda, que releemos cual Sísifo sin que nos lleve más que al punto en que debemos volver a leerla, porque ningún símbolo literario verdaderamente importante se agota en rigor.

«Tout l'art de Kafka est d'obliger le lecteur à relire» (Camus, 1951, p. 114): todo el arte de los demás también. Se trata de hacer del lector un Sísifo dichoso, y la verdad es que cuando lo decimos en relación con la lectura, la posibilidad no resulta tan extraña como cuando Camus lo pretendía en términos generales. ${ }^{3}$ Un profesor de literatura española como yo, que ha dictado más de veinte veces un curso sobre el Quijote, puede dar fe de ello. Releer es una dicha, y es una dicha saber, cuando se está releyendo, que se habrá de releer de nuevo. Y de nuevo y de nuevo y de nuevo... El horror más bien lo causaría pensar que el libro se agotará por algo diferente a la falta de tiempo: horror de que algo que no sea la muerte le ponga punto final a las relecturas.

Camus ha profundizado en el tema del artista ante el absurdo de crear sabiéndose condenado a la nadería de su esfuerzo. A ello dedica primordialmente el apartado "La création sans lendemain»:

\begin{abstract}
«Travailler et créer " pour rien », sculpter dans l'argile, savoir que sa création n'a pas d'avenir, voir son œuvre détruite en un jour en étant conscient que, profondément, cela n'a pas plus d'importance que de bâtir pour des siècles, c'est la sagesse difficile que la pensée absurde autorise. Mener de front ces deux tâches, nier d'un côté et exalter de l'autre, c'est la voie qui s'ouvre au créateur absurde. Il doit donner au vide ses couleurs.» (Camus, 1951, p. 104).
\end{abstract}

Mi pequeña contribución aquí ha consistido en proponer que su pensamiento al respecto del Sísifo como creador puede comprender no solamente al escritor, sino también al lector, ese segundo creador absurdo. Esto surge a propósito del abordaje camusiano de Kafka.

\section{Lectura camusiana de $E$ l castillo}

Me refiero ahora más propiamente a la forma en que Camus lee El castillo. Pues aunque el símbolo kafkiano no se agote y la relectura se imponga una y otra vez, el lector sí puede dar cuenta de lo que un determinado paso por ese texto le ha provocado, y eso es lo que hace $E l$ mito de Sísifo.

Camus efectúa un pequeño rodeo en el que insiste sobre la dificultad de hablar sobre el símbolo en Kafka, dado que en este autor los acontecimientos extraordinarios son asumidos como naturales por parte de los personajes (el ejemplo por antonomasia: Gregorio Samsa que despierta convertido en insecto y casi enseguida está pensando en la manera que afectará eso su trabajo como viajante de comercio). Pero es que en esto se basa precisamente el símbolo kafkiano: hay que interpretar lo que simboliza un mundo en el que lo extraordinario no provoca el asombro. ${ }^{4}$

Enseguida, Camus se inclina por una lectura de El castillo como "teología en acción". El alma del hombre en busca (inútil, imposible, malograda) de su gracia. Nada demasiado diferente de la lectura propuesta por Max Brod, pero agregándole el elemento que acerca a Kafka al plano de lo absurdo: en el autor checo, 
la incoherencia propia de esta condición humana surge al unir lo extraordinario y lo natural, así como lo universal y lo individual, lo trágico y lo cotidiano, lo lógico y lo ilógico. El lector de Kafka no deja de enfrentarse a la narración de eventos que, siendo ilógicos, se cuentan como si fueran lógicos; siendo trágicos, se hacen pasar por cotidianos; siendo extraordinarios, se aceptan como naturales; siendo universales, no pasan de dar cuenta de lo más personal e íntimo. Camus hace así de Kafka uno de los suyos, muy en la línea del procedimiento borgesiano descrito justamente en el famoso ensayo "Kafka y sus precursores": allí Borges (1961) explica cómo Kafka cambia la forma de leer textos previos a él; aquí, y aunque después parece que se desdice, Camus se inclina a leer a Kafka como un autor que ejemplifica la condición absurda de que trata El mito de Sísifo. Camus convierte a Kafka en uno de sus precursores. ${ }^{5}$

En este apéndice final de El mito de Sísifo, se describe una progresión en la obra kafkiana que resulta muy interesante para la comparación que estoy desarrollando. Pues se aborda primero La metamorfosis como el relato en el que se presenta el problema; luego, El proceso lo desarrolla hasta sus últimas consecuencias; pero es, finalmente, El castillo el texto que prescribe un tratamiento para ello, que si bien no es exitoso (ya que el problema no se termina), al menos permite convivir con este. El agrimensor es el único personaje kafkiano que consigue -según Camus - enamorarse de su condición absurda, de su perpetua persecución de una gracia divina que se le esconde y que llega a buscar hasta en el rostro más terrible de la divinidad, no el dios de bondad y belleza que imaginan los optimistas, sino el dios indiferente, el injusto, el que odia al hombre. Su esperanza no decae aunque se sepa Sísifo, condenado a seguir buscando sin resultados el consuelo o el odio divinos.

$\mathrm{Y}$ aquí, ya muy cerca del final, Camus abre una puerta que en su opinión lleva más allá de Kafka. Pues este no ha podido visualizar nada más que lo sobrenatural como respuesta: Dios. "Il n'est rien qui ne soit à Dieu", dice
Camus sobre Kafka (1951, p. 120). Camus quiere ir más allá. La siguiente cita nos deja ver su camino:

...l'œuvre tragique pourrait être celle, tout espoir futur étant exilé, qui décrit la vie d'un homme heureux. Plus la vie est exaltante et plus absurde est l'idée de la perdre. C'est peut-être ici le secret de cette aridité superbe qu'on respire dans l'œuvre de Nietzsche. Dans cet ordre d'idées, Nietzsche paraît être le seul artiste à avoir tiré les conséquences extrêmes d'une esthétique de l'Absurde, puisque son ultime message réside dans une lucidité stérile et conquérante et une négation obstinée de toute consolation surnaturelle. (Camus, 1951, p. 123-124).

Camus encuentra en Nietzsche la ruta que sigue en El extranjero, para ir más allá de Kafka, quien no puede alejarse de Dios: la vida de quien -este es Meursault — no pretende nada del más allá.

\section{Más allá del castillo, más acá del mundo}

Comencemos este apartado por un aforismo kafkiano 6: "Hay dos pecados humanos capitales de los cuales se derivan todos los demás: la impaciencia y la indolencia. Por la impaciencia los expulsaron del paraíso, por indolencia no vuelven a él. Aunque en realidad quizá solo haya un pecado principal: la impaciencia. Por la impaciencia los expulsaron, por la impaciencia no vuelven." (2006, p. 25) 7 .

Este aforismo nos puede servir para leer tan apretadamente como queramos El castillo, si seguimos la línea inaugurada por Brod y continuada por Camus, que propone que la novela es una gran alegoría de la busca de la gracia (perdida, según la tradición hebrea, en la expulsión del paraíso). ${ }^{8}$ Esa pérdida es anterior a El castillo; aquí se nos dice que se produjo por impaciencia, la que no consintió en esperar a que Dios hiciese su voluntad sobre los seres del Edén y quiso tomar la iniciativa de ir a buscar el fruto prohibido. Al inaugurarse la acción en El castillo, está claro que los aldeanos son indolentes, tibios o negligentes cuando de 
retornar a esa gracia se trata, visto que $\mathrm{K}$. es el único que realmente quisiera ingresar en el castillo: los otros se conforman con pasar la vida lo más a salvo posible de ese poder superior que los amenaza, y al que quisieran evadir. ${ }^{9}$ En una segunda consideración, el aforismo se corrige y atribuye de nuevo el problema a la impaciencia, ese pecado tan característico de K. El incorregiblemente impaciente agrimensor se condena a no obtener la gracia por causa de esa terquedad e insistencia tan propias de su carácter: algo que se nos puede pasar por alto es que toda la acción de El castillo (por mucho que psicológicamente tengamos otra impresión) transcurre a lo largo de apenas seis días. En este plazo, el agrimensor recibe comunicaciones de Klamm, se le nombra bedel de la escuela, se le asignan dos asistentes, se le envía un mensajero... Realmente, el castillo no es sordo ante su llegada; él es quien tiene una impaciencia enorme por que su situación se resuelva en un plazo brevísimo y en su conducta no deja de haber un reto constante hacia la autoridad: ¿por qué, si no por rebeldía, convierte a la amante de Klamm en su amante?

Descrito así el planteamiento de $E l$ castillo, vayamos más allá con Camus y $E l$ extranjero. O más acá, si se quiere ser más preciso. Pues Meursault sabe que no hay más allá: nunca ha regido su vida por la esperanza de obtener la gracia de una divinidad inexistente. $\mathrm{Su}$ actitud, no obstante, aparece muy bien descrita por el segundo pecado capital de que nos habla el aforismo kafkiano, y aquí podemos echar mano de todas las acepciones del término alemán, sin que ninguna deje de aplicarse al personaje: indolente, indiferente, negligente, tibio, dejado. El español de Costa Rica también nos puede ayudar: se le pasea el alma por el cuerpo.

Arriesgaré una explicación de esa conducta. Meursault representa al individuo incapaz de ir más allá en procura de la divinidad, pero, también a aquel que es incapaz de ir más allá de las apariencias. Su vida gira en torno solamente a lo que se le presenta como evidente, y no desea profundizar en nada de lo que aparece a sus sentidos. El mundo pasa ante él, que lo mira con indiferencia, sin pretender cambiar nada, sin siquiera ejecutar un juicio, interactuando solamente llevado por las circunstancias: si su madre muere (y aquí comienza la narración), él no tiene nada que decir sino lo evidente, por ejemplo, que un telegrama le informó de la situación, que se desplazó en autobús hasta el asilo donde ella vivía, que hacía mucho calor durante el entierro. Si le hace el amor a una mujer poco después, solamente puede hablar del placer que le produce el encuentro. Si escucha a Raymond, un chulo, sin emitir ningún juicio acerca del trato que da este a las mujeres y, en particular, a una amante a la que le pega, es porque la situación no le compete más que en relación con lo más evidente: las cosas son como son y a él no le interesa intervenir para cambiarlas. Se deja llevar. Y dejándose llevar es como comete un asesinato: mata al árabe sin más razón que la circunstancia de que tenía mucho calor, el tipo lo amenazaba, había una pistola en su mano...

Camus retrata así a quien, puesto en el mundo, no solamente no se pregunta por las razones de este y mucho menos trata de cambiarlo, sino que tampoco se pregunta por las razones de su propio ser. Es extranjero ante sí mismo: tan incapaz es de conocer lo que hay en el fondo de lo que lo rodea, incluidas las personas, como lo que hay en su propio interior. No expresa sus sentimientos; casi no tiene reacciones. Camus nos había anunciado a este tipo de personaje en El mito de Sísifo, identificándolo con los ayudantes de K.: aquellos que solamente se dedican a la diversión en el sentido pascaliano, pues se contentan con la apariencia antes que ir en procura de la realidad. Meursault no llega ni a plantearse una diversión constante, quizás porque en el fondo (y aquí se separaría el personaje de las ideas de Pascal $)^{10}$ no siente angustia alguna al pensar en su destino mortal. Simplemente, no piensa en ello. Esto le imposibilita incluso el sentimiento: ni se le da la muerte de su madre, ni el amor por Marie. Del deseo carnal, de sentir el agua en su cuerpo, de irritarse con el calor, de disparar el arma sin albergar remordimiento alguno, no pasa. Es un extranjero a todo lo demás. 
Esta actitud de Meursault cambiará justo hacia el final de la novela. Y lo hace precisamente en el momento en que lo vemos irritado por única vez. Su enojo lo produce el cura que lo visita en su celda de condenado a muerte, quien neciamente insiste en proponerle el asumir el fin que se le aproxima desde la perspectiva de quien espera una vida después de la muerte. Es entonces cuando Meursault da un salto cualitativo en su forma de asumir la existencia: piensa profundamente acerca de su madre (con cuya muerte se inició la narración, pero en la cual nunca reflexionó hasta ahora) y entiende la necesidad fundamental de buscar la felicidad en lo inmediato de un mundo que es indiferente ante los seres humanos. Con la muerte ahí, ya anunciada, el condenado entiende la felicidad como una experiencia ante la cual no debería ser uno indiferente. No es tarde, pero se ha perdido de mucho: no le quedan sino unas horas antes de que -según su previsión-- la multitud se enardezca con gritos de odio que piden su asesinato...

Entonces, si Meursault parte de negar la existencia de esa gracia divina que tanto sofocó a K., su primera actitud, de profunda indolencia, tibieza, dejadez en todos los ámbitos (y tal vez el que más choca sea el ámbito ético: he aquí a un personaje para quien resulta indiferente colaborar o no en el castigo corporal que un chulo le propina a una mujer, y para quien cometer un asesinato parece no revestir una mayor importancia), retrata una vida vivida en las apariencias, que solo se torna profunda cuando toma conciencia de estar efectuando una negación vehemente del más allá. No se trata pues, en $E l$ extranjero, meramente de negar a Dios, lo cual se puede hacer desde las apariencias: al fin, Dios es quien menos se nos muestra en el paisaje, salvo en opinión de los psicóticos. Se trata de tener una conciencia de esa negación que nos abra las puertas de la felicidad en la brevedad de este mundo.

Hemos hablado del símbolo kafkiano. Llegó el momento de ocuparse del símbolo camusiano expuesto en $\mathrm{El}$ extranjero. ${ }^{11} \mathrm{La}$ historia de este hombre arrojado a un mundo con el cual no establece nexos afectivos, y para el cual todo es extraño; la historia de este extranjero a todo, que no toma conciencia de poder abrir la puerta de la felicidad hasta el momento previo en que se ejecute su condena de muerte, y esto porque entonces se da cuenta de lo que implica el no creer en Dios ni esperar nada del más allá, es una historia que bien podemos entender simboliza la condición humana. Meursault representa el riesgo que ronda al ateo de caer en la indolencia, pues por no tener nada que buscar en un más allá podría tampoco abocarse a la felicidad y al bien en el más acá. Como una variante de K. a quien se le hubiera hecho ver no que es difícil o imposible ingresar en el castillo, sino que el tal castillo no existe, y por eso perdiese todo afán, y se anulase su voluntad en grado casi total. Pero el punto es que -dado este caso-suponemos que K. tendría algún tipo de reacción, precisamente porque sería muy consciente de haber perdido la posibilidad de obtener la gracia que busca; en cambio, Meursault solo se da cuenta de ello hacia el final de la novela, cuando su condena es inminente.

Puedo decir entonces que Meursault simboliza los riesgos del ser humano que ha asumido como evidente la ausencia de la gracia divina. Ello podría convertirlo en un indolente, un extranjero ante los afectos y ante los deberes: Meursault es incapaz de amar (a su madre, a Marie) tanto como es incapaz de rebelarse ante el mal que el chulo de Raymond efectúa y que él mismo llega a ejecutar, ese absurdo asesinato "porque sí". Pero no muere sin saber que esa ausencia de más allá le abría una puerta a la felicidad de lo inmediato: la irritación que le produjo la intromisión del cura en sus asuntos tuvo ese efecto beneficioso. Ironía finísima con la que cierra El extranjero: hay que agradecerle al sacerdote el haber sabido sacar de sus casillas a Meursault, algo que antes nadie consiguió, para que al menos poco antes de morir tuviese la lucidez de saberse dichoso de esa manera efímera que es la única a que podemos aspirar. 


\section{Conclusiones}

Camus toma a Kafka para traerlo a su territorio absurdo. La llegada no es violenta ni forzada: cualquier lector de Kafka sabe que la incoherencia campea en los alrededores del castillo como la cosa más normal del mundo. Se sabe que el lenguaje cotidiano de Kafka es el de la paradoja; Camus puede cómodamente leer esa paradoja en los términos de su propio pensamiento filosófico. ${ }^{12}$

Camus mira en Kafka al creador más claro de un símbolo que no se agota, producido por un creador cuya identificación con Sísifo es tan solo una variante de la identificación general del ser humano con el condenado a repetir, hasta la muerte, trabajos que no conducen a ningún fin perdurable. ${ }^{13} \mathrm{Me}$ he atrevido a sugerir que este destino del creador también es el destino del lector, lo que me permitió entender en un caso concreto la dicha que Camus quiere convencernos que se puede obtener en ello.

Camus no lleva la lectura de El castillo demasiado lejos, en la medida en que la plantea en los términos de Brod: el hombre en procura de recuperar la gracia divina, perdida desde la expulsión del paraíso. El agotador destino de quien se extravía por ir en busca de algo inexpugnable.

Camus quiere partir, en El extranjero, de una evidencia por completo ajena a K., aunque quizás no al lector de El castillo: no hay tal castillo, la gracia divina no puede hallarse porque Dios no existe, ni existe el más allá. La aldea es todo lo que tenemos y nuestra vida no durará más que un breve tiempo en ella, después de lo cual no hay nada esperándonos. ${ }^{14}$

Camus nos muestra, en El extranjero, que saber que $K$. se engaña al esperar un más allá y al vivir en razón de esta expectativa, no basta para no extraviarse. K. se pierde -quiero decir, pierde la vida, en la medida en que solo sabe perseguir un fin inalcanzable--, pero hay otras muchas maneras de perderse, y Camus nos presenta en Meursault a alguien que también se pierde, pierde la mayor parte de la vida, sin haber tomado el camino de K. Hay muchas formas de ir mal encaminado. La indiferencia, la indolencia, la dejadez ante el hecho de que el mundo no trascenderá de ninguna manera son peligros que se ofrecen al ser humano que renuncia a esperar esa trascendencia hacia lo divino. Más bien tarde que temprano, Meursault se da cuenta.

Si el creyente, según Kafka, está destinado a tocar sin resultado alguno a las puertas de ese castillo donde se aloja la gracia divina y ha de perder la vida en ello, el ateo, según Camus, corre el riesgo de caer en las garras del "cualquier cosa da igual: al final la muerte acabará con mis esfuerzos" y por lo tanto abrazarse a la indiferencia en todos los planos (afectivo, moral, incluso cognoscitivo ${ }^{15}$ ). Quizás sea tarde al descubrir que, si no hay un dios para asegurar la trascendencia, entonces es esa intrascendencia la que le da el valor a la vida, y la felicidad posible estriba en darse cuenta y vivir acorde a esto.

Lejos está Camus de pretender explorar la espiritualidad judía, como -no sabremos jamás hasta qué punto-lo quiso hacer Kafka. Pero, me permito especular con que la diferencia más pronunciada entre estos dos grandes escritores estriba en que Kafka quiso demostrar en $E l$ castillo que el mayor pecado era la impaciencia, mientras que Camus quiso demostrar en $E l$ extranjero que lo era la indolencia. La hesitación kafkiana en el aforismo que he traído a colación, que al enumerar las faltas primero le agrega la indolencia a la impaciencia, y luego se corrige y la quita, de alguna manera crea otro puente entre ellos, aunque no sea más que el de una ambigüedad que no procede a tachar y corregir (Kafka pudo haber reescrito y proponer tan solo el pecado de impaciencia) sino que prefiere dejar constancia de sus dudas. Si la ambigüedad es una riqueza, como lúcidamente pretende Borges, en este caso está enriqueciendo nuestra comparación.

\section{Notas}

1. Véanse Politzer (1960, pp. 50 ss), Simon (1991), Stern (1998, pp 191 ss) Reilly (2003, pp. 137 ss), Reilly (2003, p. 139) y Yalom (2003). 
2. En carta dirigida a Madame Herbert Dieckmann, en 1951, Camus escribe: "Madame, Je vous remercie de votre lettre et je me permettrai d'y repondre sans autres formalités./ 1) J'ai lu Kafka à 25 ans (1938) et je l'ai lu en français. Le procès m'a frappé, l'œuvre complète m'a donné l'idée d'un écrivain extrêmement limité. Pour vous donner un exemple clair, je considère que Melville s'est proposé la même entreprise que Kafka mais y a reussi parce qu'il l'a inscrite à la fois dans l'ombre et le soleil; Kafka ne sort pas de la nuit.» (Jones, 1998, p. 646).

El panorama de la producción literaria y filosófica de este primer gran periodo camusiano se completa con dos obras teatrales: El malentendido y Calígula. A la trama de la primera de ellas se hace una referencia explícita en El extranjero.

3. Véase Genovese (2010) para una explicación más detallada de cómo el mito de Sísifo se puede mirar con aprecio, según Camus. También en esta línea Scott (1959).

4. Tengo que decir que yo no veo por qué esto haría del símbolo kafkiano un símbolo especialmente difícil, como pretende Camus.

5. No solamente a Kafka. Lo hace con Dostoievski y Tirso también, entre otros. En cuanto a que Camus se desdice de tal, me refiero a que más adelante en el ensayo califica con un ambiguo "probablemente" el que la obra kafkiana no sea absurda.

6. Jordi Llovet, en un esclarecedor prólogo de la traducción castellana de Adán Kovacsics, Joan Parra y Andrés Sánchez Pascual, relaciona la redacción de los aforismos kafkianos con la lectura de “...historias y cuentos hasídicos -el hasidismo es la corriente mística más importante entre los judíos del este de Europa en los siglos XVIII a XX--..” (Kafka, 2006, p. 8) Kafka explora de manera originalísima la espiritualidad judía. No está de más señalar que un autor como Harold Bloom declara que esta es la parte más importante de la producción de Kafka, acaso porque piensa que este no hizo otra cosa en la vida más que explorar la espiritualidad judía.

7. El término alemán es "Lässigkeit", que se puede traducir como "indolencia", pero, también como "negligencia", “dejadez", "tibieza". El primer pecado, "Ungeduld", tiene una traducción menos dudosa: es "impaciencia".
8. Una buena síntesis del abordaje de Brod está en Thieberger (1967, p. 323).

9. Me refiero a los otros que no forman parte del cuerpo de autoridades del castillo. Estas ya se encuentran en una posición de privilegio en relación con ese poder superior, pero aún así jamás se aclara cuánto acceso (¿será real o fingido?) tienen a él. Muchas veces dan la impresión de estar asustando con la vaina vacía: dicen ostentar el poder del castillo, pero no parece que conozcan demasiado bien esa instancia.

10. Jean du Roustu calificó a Camus de "Pascal sin Cristo". Véase Peyre (1958, p. 477).

11. Para una exploración completa del concepto de símbolo en Camus, véase Eubanks y Petrakis (1999).

12. Ejemplos de paradoja en la obra kafkiana abundan; me permito transcribir aquí uno de los más elegantes, de un aforismo: "Una jaula salió en busca de un pájaro". (2006, p, 28)

13. En el mito Sísifo es inmortal, pero, obviamente en el pensamiento de Camus el ser humano no lo es.

14. En otro ensayo, "El castillo no existe" (Víquez, 2014), profundicé en la forma cómo el texto kafkiano podría conducir a su lector a tales conclusiones; es decir, la posibilidad de que el lector de Kafka descubra que sabe más que $K$., ya que este se engaña al dar por buenas las declaraciones nunca comprobadas de quienes le aseguran que hay un castillo.

15. A menudo Meursault renuncia, de buenas a primeras, a hacer averiguaciones. Su curiosidad, tanto como su compromiso con el bien y su participación emocional, son prácticamente nulos.

\section{Bibliografía}

Blanchot, Maurice .1981. De Kafka à Kafka. Paris: Éditions Gallimard.

Bloom, Harold. 1995. El canon occidental. Trad. de Damián Alou. Barcelona: Anagrama. 
Borges, Jorge Luis. 1961. Otras inquisiciones. Buenos Aires: Emecé.

Camus, Albert. 1951. Le mythe de Sisyphe. Paris: Éditions Gallimard.

Camus, Albert. 1957. L’Étranger. Paris: Éditions Gallimard.

Camus, Albert. 1958. Caligula suivi de Le malentendu. Paris: Éditions Gallimard.

Darzins, John. 1960. "Transparence in Camus and Kafka". En Yale French Studies (25): $98-103$.

Deleuze, Gilles y Félix Guattari. 1978. Kafka. Por una literatura menor. Trad. de Jorge Aguilar Mora. México, D.F.: Ediciones Era.

DX: diccionario alemán-español en línea: www. dix.osola.com/index.es.php

Eubanks, Cecil y Peter A. Petrakis. 1999. "Reconstructing the World: Albert Camus and the Symbolization of Experience". En The Journal of Politics, The University of Chicago Press LXI (2): 293-312.

Friedman, Maurice.1970. Problematic Rebel: Melville, Dostoievsky, Kafka, Camus. The University of Chicago Press, Chicago.

Genovese, Maria K. 2010. "Meaningful Meaninglessness: Albert Camus' Presentation of Absurdism as a Foundation for Goodness" Salve Regina Pell Scholars and Senior Theses Salve' s Dissertations and Theses, en http://digitalcommons. salve. edu/pell_theses Consulta: 20 de enero de 2016.

Gillon, Adam. 1961. "The absurd and "les valeurs idéales" in Conrad, Kafka and Camus". En The Polish Review VI (3) (Summer): 3-10.
Glicksberg, Charles Irving y Harry T. Moore. 1963. The Tragic Vision in Twentieth Century Literature. Southern Illinois University Press, U.S.A.

Hochberg, Herbert. 1965. "Albert Camus and the Ethic of Absurdity". En Ethics LXXV (2): 87-102.

Isaacson, José. 2005. La realidad metafísica de Franz Kafka. Buenos Aires: Corregidor.

Jaskulski, Greta. 2009. "Depriving the Symbol of Its Power: The Dissolution of Meaning in Albert Camus's "Cycle of the Absurd"” Senior Paper presented for a Degree Bachelor of Arts with a major in Literature at The University of North Carolina at Asheville.

Jones, James F. Jr. 1998. "Camus on Kafka and Melville: An Unpublished Letter". En The French Review LXXI (4): 645-650.

Joyaux, Georges J. 1960. "Albert Camus and North Africa". En Yale French Studies (25): 10-19.

Kafka, Franz. 2006. Aforismos. Trad. De Adán Kovacsics, Joan Parra y Andrés Sánchez Pascual. Prólogo de Jordi Llovet. Barcelona: Editorial Contemporánea.

Kafka, Franz. s.f. Aphorismen, en línea: www. digbib.org/Franz_Kafka/Aphorismen_pdf

Kafka, Franz. 1981. El castillo. Trad. de J.A. Moyano Moradillo. Madrid: EDAF.

Kafka, Franz. 1992. Obras selectas. Edición de Antonio Massone. Trad. de D.J. Vogelmann. Buenos Aires: Editorial Andrés Bello. 
Murray, Nicholas. 2006. Kafka. Literatura y pasión. Trad. de Silvia Kot. Buenos Aires: Editorial El Ateneo.

Onfray, Michel. 2012. L'ordre libertaire. La vie philosophique d'Albert Camus. Paris, Flammarion.

Peyre, Henri. 1958. "Albert Camus, an AntiChristian Moralist". En Proceedings of the American Philosophical Society CII (5): 477-482.

Pingaud, Bernard. 1971. L'étranger de Camus. Paris: Classiques Hachette.

Politzer, Heinz. 1960. "Franz Kafka and Albert Camus: parables of our time". En Chicago Review XIV (1) (SPRING): 47-67.

Reilly, Patrick. 2003. The Dark Lanscape of Modern Fiction. Great Britain: Ashgate Publishing.

Rhein, Phillip H. 1972. Albert Camus. U.S.A.: Hippocrene Books.

Sala-Sanahuja, Joaquim. 2010. "Albert Camus y el absurdo del mundo". En El Ciervo, Año 59 (707): 30-31.

Scott, Nathan A. 1959. "The Modest Optimism of Albert Camus". En The Christian Scholar XLII (4): 251-274.

Simon, Ernest.1991."Palais de Justice and Poetic Justice in Albert Camus' "The Stranger"”.
En Cardozo Studies in Law and Literature III (1) (Spring - Summer): 111-125.

Stern, Daniel. 1998. "The Fellowship of Men That Die: The Legacy of Albert Camus". En Cardozo Studies in Law and Literature X (2) (Winter): 183-198.

Suárez Cázares, Luis Fernando. 2013. "Sören Kierkegaard y Albert Camus: de AntiClimacus a Sísifo". En Piezas, nueva época III (17): 78-83.

Thieberger, Richard. 1967. «Kafka, Camus, et la sémantique historique: Réflexions méthodologiques sur la recherche littéraire». En Comparative Literature Studies, Penn State University Press IV (3): 319-326.

Todorov, Tzvetan. 1991. Crítica de la crítica. Trad. de José Sánchez Lecuna. Barcelona: Editorial Paidós.

Vega, José María y Neus Carbonell. 1998. La literatura comparada: principios $y$ métodos. Madrid: Gredos.

Víquez, Alí. 2014. "El castillo no existe" En Káñina Revista de Artes y Letras XXXVIII (1): 77-94.

Yalom, Marilyn. 2003. "Albert Camus and the Myth of The Trial". En Modern Language Quarterly XXV (4): 434-450.

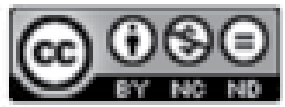

Este obra está bajo una licencia de Creative Commons Reconocimiento-NoComercial-SinObraDerivada 4.0 Internacional. 